\title{
Impact of the polymorphism in vitamin D receptor gene BsmI and the risk of systemic lupus erythematosus
}

\author{
Linhui $\mathrm{Li}^{1} \cdot$ Bin Yang ${ }^{1} \cdot$ Lanlan Wang ${ }^{1}$
}

Received: 29 January 2016 / Accepted: 31 January 2016 / Published online: 9 February 2016

(C) International League of Associations for Rheumatology (ILAR) 2016

Dear editor:

We have read with great interest the article by $\mathrm{Hu}$ et al. [1] entitled "Impact of the polymorphism in vitamin D receptor gene BsmI and the risk of systemic lupus erythematosus: an updated meta-analysis". It is a novel meta-analysis in which the authors discussed the association between polymorphism in vitamin D receptor gene BsmI (rs1544410) and the risk of SLE. After summarizing the pooled results of 9 studies with a total of 1247 SLE cases and 1687 controls, the authors suggested that no significant association was found in Caucasian or overall population, but $\mathrm{Bb}+\mathrm{BB}$ genotype and $\mathrm{B}$ allele can significantly increase the SLE risk in Asian population. However, some points should be further discussed.

After searching related keywords in PubMed database, we found one article [2] that was in accordance with the inclusion and exclusion criteria of this meta-analysis but not included by the authors. In this study by Emerah et al. [2], the authors performed genotyping of VDR gene BsmI polymorphism in 107 SLE cases and 129 controls. It is found that B allele and $\mathrm{B}$-containing genotypes (BB and $\mathrm{Bb}$ genotype) would be a risk factor for SLE.

Subsequently, we performed statistical analysis after including the forementioned study with a total of 1354 SLE cases and 1816 controls. In the dominant model $(\mathrm{Bb}+\mathrm{BB}$ versus $b b)$, it is demonstrated that there was a significant as-

Lanlan Wang

wanglanlanhx@163.com

1 Department of Laboratory Medicine, West China Hospital, Sichuan University, 610041 Chengdu, China sociation between BsmI polymorphism (rs 1544410) with SLE risk among the overall population (pooled $\mathrm{OR}=1.78,95 \%$ $\mathrm{CI}=1.07-2.96$ ) but not in Caucasian subgroup (pooled $\mathrm{OR}=1.06,95 \% \mathrm{CI}=0.68-1.63)$. In the recessive model ( $\mathrm{BB}$ versus $\mathrm{Bb}+\mathrm{bb}$ ), it is shown that there was no significant association between BsmI polymorphism (rs1544410) with SLE risk among the overall population (pooled $\mathrm{OR}=0.97$, $95 \% \mathrm{CI}=0.76-1.23$ ) or Caucasian subgroup (pooled $\mathrm{OR}=1.00,95 \% \mathrm{CI}=0.63-1.60)$. In addition, a significant association between $\mathrm{B}$ allele and the SLE risk was found in the overall population (pooled $\mathrm{OR}=1.49,95 \% \mathrm{CI}=1.02$ 2.17) but not in Caucasian subgroup (pooled $\mathrm{OR}=1.03$, $95 \% \mathrm{CI}=0.74-1.44)$. The results in the subgroup of Asian did not change.

We thank the authors for their important research. However, we consider that it is of importance to raise this issue to clarify the results of the study.

Compliance with ethical standards

Disclosures None.

\section{References}

1. Hu W, Niu G, Lin Y, Chen X, Lin L (2015) Impact of the polymorphism in vitamin D receptor gene BsmI and the risk of systemic lupus erythematosus: an updated meta-analysis. Clin Rheumatol: $1-8$.

2. Emerah AA, Amal S (2013) Role of vitamin D receptor gene polymorphisms and serum 25-hydroxyvitamin D level in Egyptian female patients with systemic lupus erythematosus. Mol Biol Rep 40:6151-6162 